\title{
Notes on the First Forum: $Q i$ in the Oracle-Bone Inscriptions
}

We are excited in presenting our first Forum on Qi in the Oracle-Bone Inscriptions to our readers. This Forum is under the guidance of the world renowned Oracle-Bone Inscriptions (ОВI) scholar cum retired Board Director of the Li Fang-Kuei Society for Chinese Linguistics (LFKS), Ken-ichi Takashima, who secured the right of publication of two unpublished papers on $Q i$ by the eminent OBI historian-sinologist cum Macarthur Fellow, the late Professor David N. Keightley (1932-2017), through his two sons. We are indebted to Steven Keightley and Richard Keightley for their generosity in affording us the permission for and honor of publishing these precious papers by their esteemed father in our B(ulletin) of C(hinese) $L$ (inguistics).

These valuable papers are from the archive of Takashima, who was given a copy of the manuscripts by Professor Keightley. These manuscripts, meticulously scanned by Professor Jing Zhichun of the University of British Columbia, to whom we are much indebted, contained handwritten notes added by Takashima. Removing the handwritten notes in order to publish the unmodified original manuscripts posed a difficult problem, which was finally solved by Ryan Rui-wen $\mathrm{Wu}$, a Research Fellow of the Academia Sinica cum LFKS Board Director and $B C L$ Forum Editor, who spent three weeks cleaning up the manuscripts carefully and meticulously and to whom we owe our deep gratitude.

The original page numbers of the two Keightley papers provide crucial information for the reading of these two papers and are thus given in parentheses on each page. 